\title{
Experimental and computational investigation of waste heat recovery from combustion device for household purposes
}

\author{
S. K. Singh ${ }^{1} \cdot$ S. C. Kaushik ${ }^{1} \cdot$ V. V. Tyagi $^{2} \cdot$ S. K. Tyagi $^{1}{ }^{\circledR}$
}

Received: 23 April 2021 / Accepted: 12 September 2021 / Published online: 11 October 2021

(c) The Author(s), under exclusive licence to Islamic Azad University 2021

\begin{abstract}
Waste heat recovery along with low-grade energy can be utilized for numerous applications in our daily life. This manuscript presents a novel idea of utilizing the waste heat from domestic cooking devices for assisting the solar desalination system through simulation and validated experimentally. To assess the potential of waste heat from a 2D axisymmetric model of water jacket has made using ANSYS Fluent while applying the user-defined function (UDF) to the outermost wall of the cookstove having the temperature as high as $340{ }^{\circ} \mathrm{C}$ during the operation. Further, to ensure the recovery of the waste heat, without affecting the performance of the cookstove, an air gap of $0.05 \mathrm{~cm}$ was provided between the combustion chamber and the water jacket. The efficiency of the original cookstove without air gap was found to be $\sim 33 \%$, which enhanced up to $43.79 \%$ without flow of water in the jacket, and finally reached up to $56 \%$ when water flows in the jacket. This indicates that the arrangement used in this particular study has not only recovered the waste heat but also improved the overall performance by $\sim 69.34 \%$, without disturbing the cooking phenomenon.
\end{abstract}

Keywords Waste heat recovery $\cdot$ Water jacket $\cdot$ Thermal imaging test $\cdot$ Biomass cookstove $\cdot$ Thermal performance

\author{
Abbreviations \\ $\eta \quad$ Thermal efficiency of cookstove \\ $n \quad$ Total number of vessel used during the experiment \\ $C_{\mathrm{w}} \quad$ Specific heat of water $(4.18 \mathrm{~kJ} / \mathrm{kg})$ \\ $C_{\mathrm{v}} \quad$ Specific heat of the aluminum vessel \\ $m_{p} \quad$ Mass of vessel along with lid $(\mathrm{kg})$ \\ $m_{\mathrm{w}} \quad$ Mass of water in the vessel $(\mathrm{kg})$ \\ $m_{\mathrm{h}} \quad$ Mass of hot water received in the vessel $(\mathrm{kg})$ \\ $X_{\text {fuel }} \quad$ Mass of solid fuel consumed $(\mathrm{kg})$ \\ $X_{k} \quad$ Mass of petrol for ignition $(\mathrm{kg})$ \\ $H_{\text {fuel }}$ The calorific value of solid fuel $(\mathrm{kJ} / \mathrm{kg})$ \\ $H_{k} \quad$ Calorific value of petrol $(\mathrm{kJ} / \mathrm{kg})$ \\ $p \quad$ Static force \\ $\vec{F} \quad$ External body forces \\ $\rho \vec{g} \quad$ Gravitational body force \\ $W_{\mathrm{H}} \quad$ Weight of hot water obtained by the vessel along \\ with lid (kg)
}

S. K. Tyagi

sudhirtyagi@yahoo.com

1 Department of Energy Science and Engineering, Indian Institute of Technology Delhi, Hauz Khas, New Delhi 110016, India

2 School of Energy Management, Shri Mata Vaishno Devi University, Katra 182320, Jammu and Kashmir, India

$\begin{array}{ll}T & \text { Absolute temperature of sampled gas, in K } \\ S_{\mathrm{m}} & \text { Mass added to the continuous phase from the dis- } \\ & \text { persed second phase } \\ \rho & \text { Density } \\ K & \text { Thermal conductivity } \\ \tau & \text { Transmissivity } \\ g & \text { Gravity }\left(9.81 \mathrm{~m} / \mathrm{s}^{2}\right) \\ t_{1} & \text { Initial temperature of water }\left({ }^{\circ} \mathrm{C}\right) \\ t_{2} & \text { Final temperature of water }\left({ }^{\circ} \mathrm{C}\right) \\ t_{3} & \text { Final temperature of water in the last vessel after } \\ & \left.\text { the test ( }{ }^{\circ} \mathrm{C}\right) \\ t_{4} & \text { Final temperature of water obtained from the water } \\ & \text { jacket } \\ \underline{\bar{\tau}} & \quad \text { Dissipation mechanism } \\ & \text { Stress tensor }\end{array}$

\section{Introduction}

In modern society, energy is one of the critical elements ensuring the minimum living needs of the people, such as cooking, heating, cooling, and thermal comfort, globally. In social relations, similar uses of energy are found for different cultural and religious events. Therefore, biomass has been the main source for supplying and meeting the energy 
demands for both heating and cooking requirements, culturally for centuries. Even today, around $40 \%$ of the global population is using traditional cookstoves to meet their day-today cooking and heating requirements, globally. Also, more than two-thirds of the Indian household still use conventional biomass cooking stoves to cook their meals through the burning of solid fuel such as dung, coconut husk, agro waste, and palm waste. Almost all biomass energy sources used for domestic energy purposes and craft industries in developing countries exist in solid form, which accounts for $56 \%$ of total biomass energy $[1,2]$. The recent data indicate a steady decline in the number of people worldwide without access to clean cooking, and the pandemic caused additional challenges reversing this modest situation. There are seven times more people in developing Asia, with 1.6 billion people lacking clean cooking facilities than electricity, however, with 670 million people gaining access since 2010, the latest data show encouraging signs and access rates in India and China hit $49 \%$ and $71 \%$ in 2018, respectively [3].

In the Asian countries, around $68 \%$ of the population still use to live in rural areas and from that mainly in India, around 0.2 billion peoples use the following as a cooking fuel, like $49 \%$ use firewood, $28.6 \%$ liquefied petroleum gas (LPG), 8.9\% cow dung cake, 2.9\% kerosene, 1.5\% coal, lignite, or charcoal, $0.4 \%$ biogas, $0.1 \%$ power, and $0.5 \%$ by other means [4]. The use of biomass-based cooking is as old as about 100,000 years, which is clearly evidenced from historical findings [5]. Kumar et al. [6] have studied various processes of heat transfer in a cookstove. According to them, three modes of heat transfer are important to remember, i.e., conduction, convection, and radiation. The conduction is the heat transfer through the metal body, and convection is due to the flow of a medium, which may be a solid, liquid, gas, or a mixture of all.

On the other hand, radiation is an entirely separate phenomenon, in which the heat loss occurs from the flame and the cookstove, and this radiation travels into the gases and is absorbed from the exposed surfaces of the pot or griddle by cooler molecules. In general, the thermal efficiency of a traditional cookstove is in the range of $12-18 \%$, which means more than $82 \%$ of energy is lost due to several reasons; therefore, the heat losses from conventional cooking stoves are very high. Sedighi and Salarian [7] reported that around $14-42 \%$ of total energy is wasted from the cookstove exclusively due to conduction. Besides that, flue gases escape the cookstove without any interaction with the pot in large amounts due to unchecked combustion of carbon. Gas losses are roughly $22-39 \%$, i.e., convective loss. Due to its low thermal efficiency as well as the increasing difference between supply and demand for firewood, coupled with the lack of fossil fuels and contamination caused by conventional stoves, the technologists have been forced to concentrate their efforts on improving the thermal efficiencies of these stoves and to make more powerful smokeless stoves. This will add a positive effect on health as well as on the atmosphere due to increased thermal performance.

At present, there is only a small number of cookstove certified by the Ministry of New and Renewable Energy (MNRE) with a registered maximum thermal efficiency of 40.81 (TERI SPT 0314 Stove) for domestic size forced cookstove and 37.12 (IMPMETAL TERI SPFB 0514b) for group size forced cookstove [8]. Approximately $65-70 \%$ of thermal efficiency is lost in the atmosphere, and the temperature of the air rises, which may be detrimental to the person who directly runs the cookstove now. It is well known that the transfer of heat in a cookstove is an important phenomenon, but due to the various losses, it is necessary to do thorough research on different heat transfer processes to know the heat transfer mechanism and their utilization, if possible. According to a World Health Organization (WHO) assessment, smoke from biomass burning causes around $3 \%$ of the total global burden of illness, resulting in 1.6 million premature deaths each year, including 0.9 million children under the age of five [9]. Household air pollution, inefficient energy use, and haphazard fuel wood collection have all been identified as roadblocks to achieving Millennium Development Goals [10].

During the 1940s, India was one of the first countries to create biomass-based cookstoves. Following the oil crisis of the 1970s, more extensive research and development activities on improved cookstoves took place all over the world, resulting in the establishment of many improved cookstove programmes (ICPs) in a number of developing countries, including India, to address the energy crisis, deforestation, kitchen smoke reduction, and other issues. Despite the fact that these projects began in numerous nations and were conducted by a variety of government agencies, NGOs, and donor organizations, they were unable to meet the required objectives due to a variety of factors and constraints [11]. Improved cookstove should be built in ways that will fulfill the requirements and easy to use by the consumer $[12,13]$. Firstly, in contrast to the use of open fires, the proposed improved design must be cheap. Secondly, for a minimum of a year and ideally longer, the stove must be robust to survive constant use without cracking. The Government of India, the Ministry of New and Renewable Energy has proposed computational fluid dynamics (CFD) models for stove production work (MNRE 2010) because CFD nowadays has become an important tool for the analysis of combustion processes and many other similar phenomena. In a very precise time and price than an actual model, CFD can deliver a more broad analysis, but experimental evaluation of the CFD model is mandatory.

As per the authors' information, only few studies have been done so far, to utilize the waste heat from the outermost wall of the cookstove without altering the main purpose 
of the cookstove, i.e., cooking. Senthil Rajan et al. [14] employed a heat exchanger and a circulation pump to transfer high-temperature energy from a biomass heat source to saline water in the still at a constant current rate. Thermoelectric power generated from waste heat from a biomass dryer at a wall temperature of $180^{\circ} \mathrm{C}-200{ }^{\circ} \mathrm{C}$ has significant applications, particularly with thermoelectric cooling modules [15]. Some other researchers [16, 17] used waste heat from biomass cookstoves to create electricity using TEG, but no one used waste heat to generate hot water. The process of extracting waste heat by fabricating a water jacket around the outermost wall of the domestic type forced draft cookstove and calculation of water outlet temperature obtained from the respective water jacket has been presented in the manuscript. In this, a 2D axisymmetric model of a water jacket has been prepared using ANSYS Fluent to estimate the waste heat recovery from the domestic forced biomass cookstove, while applying the user-defined function (UDF) to the outermost wall of the cookstove ranging from 40 to $340{ }^{\circ} \mathrm{C}$, as recorded by FLIR A325sc infrared camera. The steady-state model, tested against the experimental results, forecasts the temperature of water collected at the outlet.

\section{Material and methods}

The household energy database exhibited [18] that there is a gradual decline in the number of people lacking clean cooking facilities, but attempting to undo this moderate rises due to Covid-19 pandemic, as shown in Fig. 1. The thermal performance of the cookstove depends on many factors, such as the geometry of the combustion chamber, the material used to make the burner, the insulation used to minimize thermal loss, the geometry of the pot, the fuel stack, and the pot-stove difference. Losses are having a big impact on the thermal performance of both types of cookstoves, i.e., domestic and community type. When discussing the three form of losses during cooking on cookstove; first, the

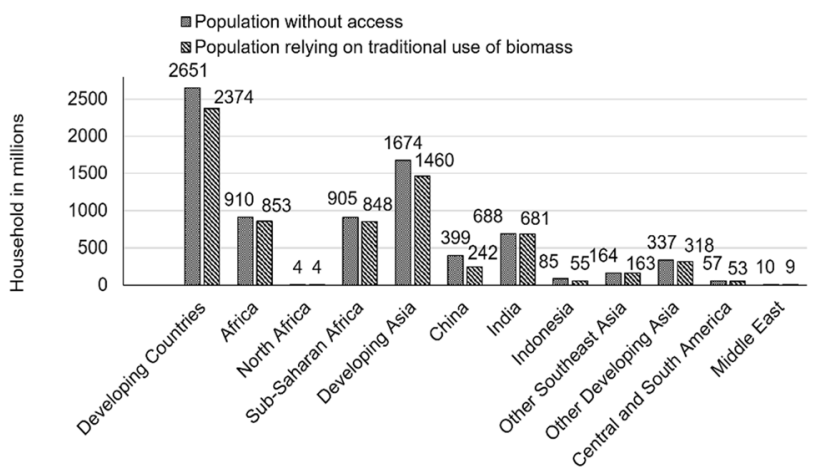

Fig. 1 Household energy database [18] conduction heat loss from the wall of the cookstove and for a variation in temperature more energy can be store by a bulky cookstove, another loss due to convective heat movement as the jet around the bottom and/or sides of the pot, where the hot gases escape outward and upward and from the distance between the pot and wall, as well as, from the exterior surfaces of pans and finally, the various fields of radiation loss, such as the radiation released by the blaze, the exchange of radiation between the wood surface and the pot, the inner walls and the loss of radiation from the wall, the pot, the chimney as well as from the combustion chamber opening to the atmosphere.

All these types of losses are shown in Fig. 2. Although the transfer of heat in a cookstove is an unpredictable phenomenon, anyone can use the following equation for understanding and estimating heat flow in a cookstove, and there are certain assumptions for using this equation:

- The phenomenon of steady-state heat transfer

- Isotropic material

- Thermal conductivity varied with temperature, but constant is assumed here.

The Sum of the release of waste heat through the stove wall is given as;

$Q_{\text {loss }}=Q_{\text {conduction }}+Q_{\text {convection }}+Q_{\text {radiation }}$

The losses also depend on cookstove fabrication materials. Here is some commonly used material for cookstove fabrication (for $k$ ), and their properties are given in Table 1 .

Apart from the aforementioned issues, the traditional cookstove has a slew of others, including longer cooking times, higher fuel consumption, and the fact that women spend a significant amount of time gathering fuel wood [19, 20]. A number of factors, including the family's income, the availability of other fuels, and the geography (rural, urban, and remote), determine the type of fuel used for cooking in a particular household. Furthermore, as family income rises,

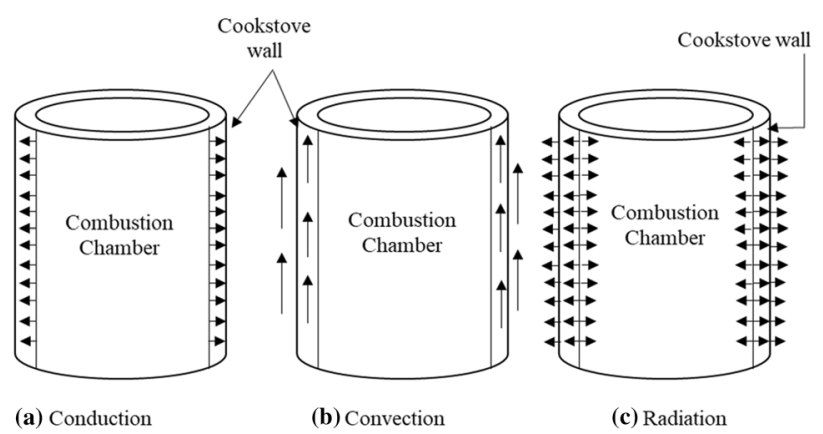

Fig. 2 Process of heat transfer in a cookstove 
Table 1 Thermal properties of commonly used material for cookstove fabrication

\begin{tabular}{lllll}
\hline S. No & Material & $\begin{array}{l}\text { Specific } \\
\text { heat }(\mathrm{J} / \mathrm{kg} \\
\mathrm{K})\end{array}$ & Density $\left(\mathrm{kg} / \mathrm{m}^{3}\right)$ & $\begin{array}{l}\text { Thermal } \\
\text { conductivity } \\
(\mathrm{W} / \mathrm{m}-\mathrm{k})\end{array}$ \\
\hline 1 & Mild steel & 502.416 & 7850 & 46 \\
2 & Cast iron & 460.548 & $6800-7800$ & 80 \\
\hline
\end{tabular}

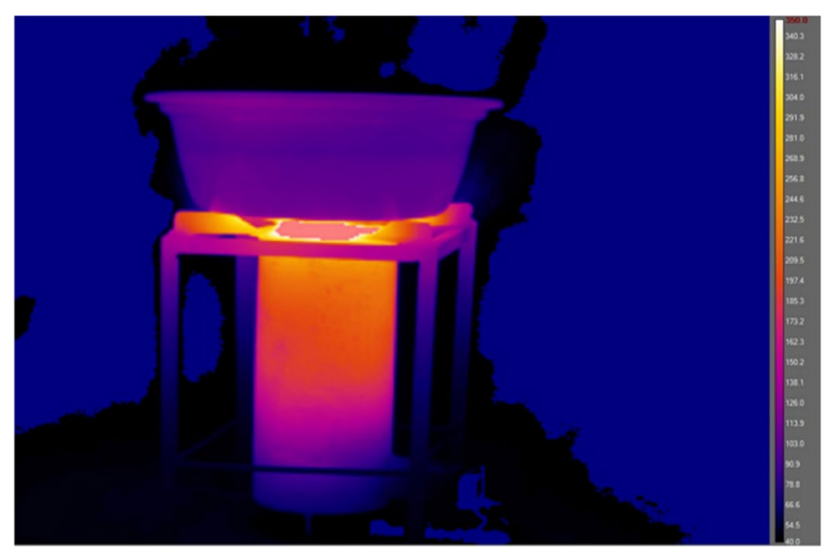

Fig. 3 Thermal imaging test of cookstove using FLIR A325sc

people transition from biomass to kerosene, coal, LPG, and natural gas, depending on the resource and degree of education [21, 22]. Although there has been a move from biomass to LPG in urban areas, people in rural and isolated areas have remained to rely on biomass fuel due to its price and availability, as well as traditional and cultural hurdles [23].

\section{Computational analysis}

The cookstove thermal imaging test has been done using FLIR A325sc Infrared cameras, and the image is displayed in Fig. 3. It is clear from Fig. 3 that a lot of heat is being lost from the cookstove outer wall and the maximum temperature reported at the top of the cookstove was approximately $350{ }^{\circ} \mathrm{C}$ and the temperature decreases as the bed move down and the lowest temperature measured at the bottom of the stove was near about $40{ }^{\circ} \mathrm{C}$. This enormous volume of heat, that is lost, can be used in multiple ways to satisfy the energy requirement for different applications. This idea motivated the authors to extract that waste heat by fabricating a water jacket around the forced draft domestic cookstove, keeping some air gap so that it would not interrupt the natural cooking process. The hot water can be used for dishwashing, cloth washing, bathing purposes, or it can be utilized to improve the productivity of a small solar distillation unit.

In the current simulation, the following assumptions are made:

1. The average parameters over time are more important than the instantaneous values since the activity of the cookstove is not in a steady state.

2. The average efficiency of the cookstove is therefore believed to be steady state $[24,25]$.

3. To save simulation time, a two-dimensional (2-D) axisymmetric model is used in Fluent [24, 26].

In regards to geometry creation and simulation of the cookstove, to find out the appropriate air gap and temperature of the water from the outlet of the water jacket, the design modeler and FLUENT R19.2 by forming structured quadrilateral cells were used. The $2 \mathrm{D}$ model of the axisymmetric system is shown in Fig. 4. The cookstove was taken for simulation with a fixed diameter of $0.180 \mathrm{~m}$ and a length of $0.350 \mathrm{~m}$. (one module). The schematic of the geometrical fabrication of the water jacket is shown in Fig. 5a, b. Operating pressure considered to be one bar,
Fig. 4 Schematic of a 2D axisymmetric model of fabrication of water jacket

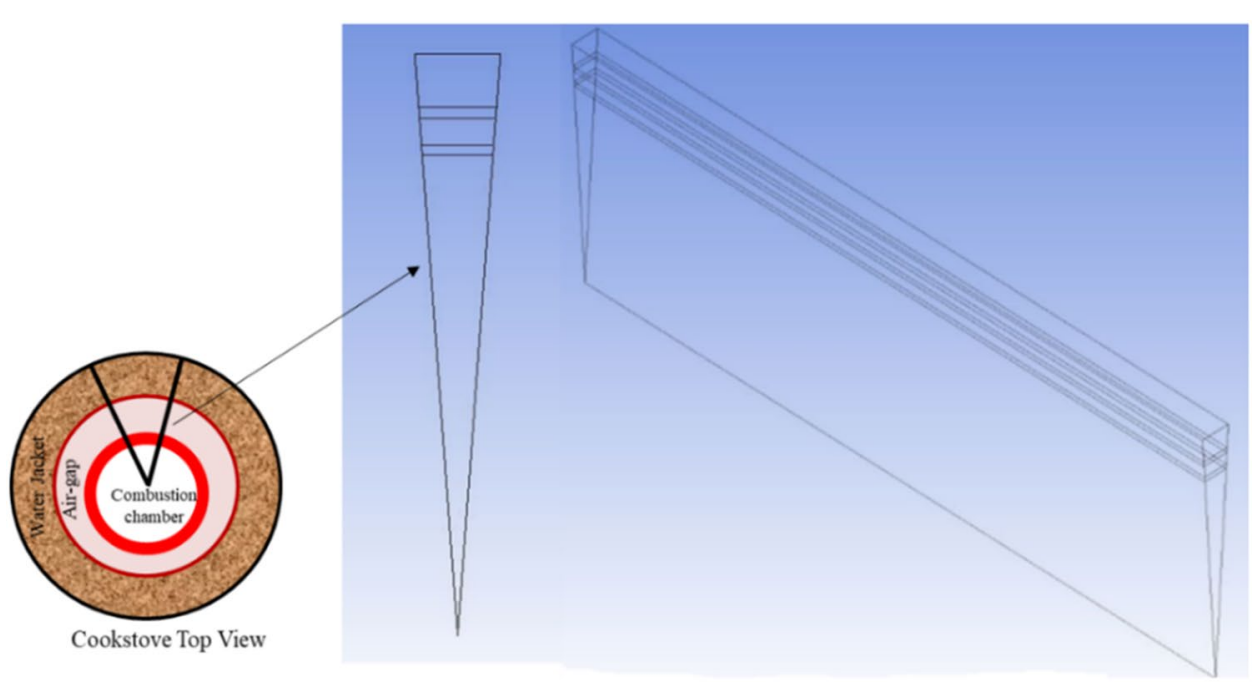




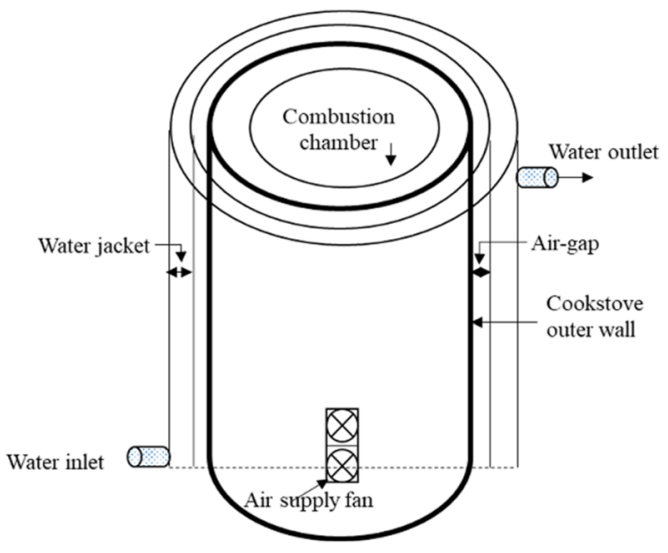

(a)

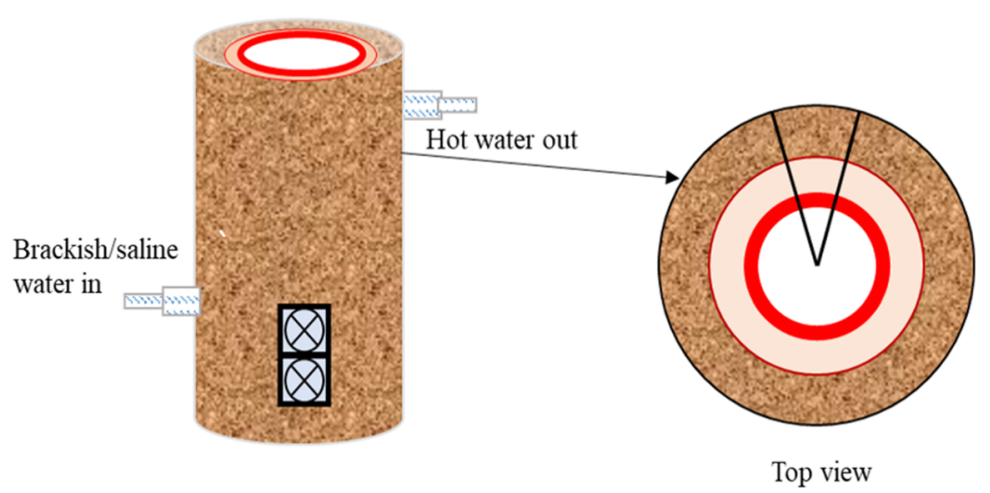

(b)

Fig. 5 Schematic of water jacket fabrication a Line diagram, b Pictorial view

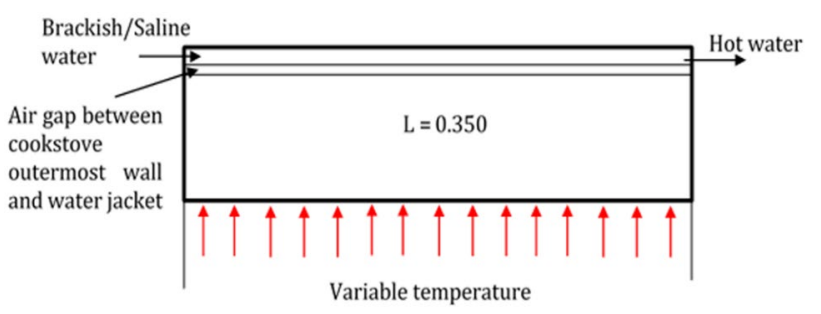

Fig. 6 Geometrical setup and boundary conditions

user define function (UDF) (as per temperature variation from top to bottom) was applied to the outer wall of the cookstove as shown in Fig. 6.

\section{Governing equation}

The governing equations, which can be stated in the general form of integral equations [27], are the source of the essential concepts of Newton's law and Reynolds law. The three equations, namely continuity, momentum, and energy, can be obtained as follows [28] using the conservation equations:

\section{Continuity conservation equation}

The mass conservation equation is applicable to both compressible and incompressible flows.

$\frac{\partial \rho}{\partial t}+\nabla \cdot(\rho \vec{v})=S_{\mathrm{m}}$

\section{Momentum conservation equation}

$\rho\left[\frac{\partial(\vec{v})}{\partial t}+(\vec{v} \cdot \nabla) \vec{v}\right]=-\nabla p+\nabla \cdot(\overline{\bar{\tau}})+\rho \vec{g}+\vec{F}$

where $\overline{\bar{\tau}}$ is the stress tensor.

\section{Energy conservation equation}

$\rho\left[\frac{\partial h}{\partial t}+\nabla \cdot(h \vec{v})\right]=-\frac{\partial p}{\partial t}+\nabla \cdot(k \nabla T)+\phi$

where $h$ (specific enthalpy) $=e+p /(\rho T)$.

\section{Experimental setup}

The current experiment was executed in the biomass combustion-testing lab (WS-206) at the IIT Delhi campus $\left(28.6139^{\circ} \mathrm{N}, 77.2090^{\circ} \mathrm{E}\right)$. To find out the efficiency, tests were carried out in a regular cookstove testing hood. The biomass cookstove has an inner and outer diameter of $0.128 \mathrm{~m}$ and $0.180 \mathrm{~m}$ with a height of $0.350 \mathrm{~m}$ and made of mild steel with a batch feeding system. In terms of primary and secondary air, fans are used to provide enough air for the combustion of biomass using a dual DC power regulator. The weighing machine has been used to calculate the fuel, cookstove, and pot weight, and to measure the water temperature, PT-100 thermocouple sensor has been used. To initiate the ignition, around $10 \mathrm{ml}$ of petrol has been used. The diagram of the cookstove with the testing hood is shown in Fig. 7, and the experimental setup is shown in Fig. S1 (supplementary material).

\section{Design of water jacket}

The fabrication of the water jacket has been done using $0.002 \mathrm{~m}$ of mild steel sheet around the outermost wall of the cookstove, retaining a sufficient air gap as per the result obtained from the simulation. The water jacket inlet and outlet are attached to a solid steel pipe. During testing, the exterior temperature of the stove was reported to be more than $104{ }^{\circ} \mathrm{C}$, which can burn consumers, so when moving or 
Fig. 7 Schematics of a hood with dilution tunnel for testing of cookstove

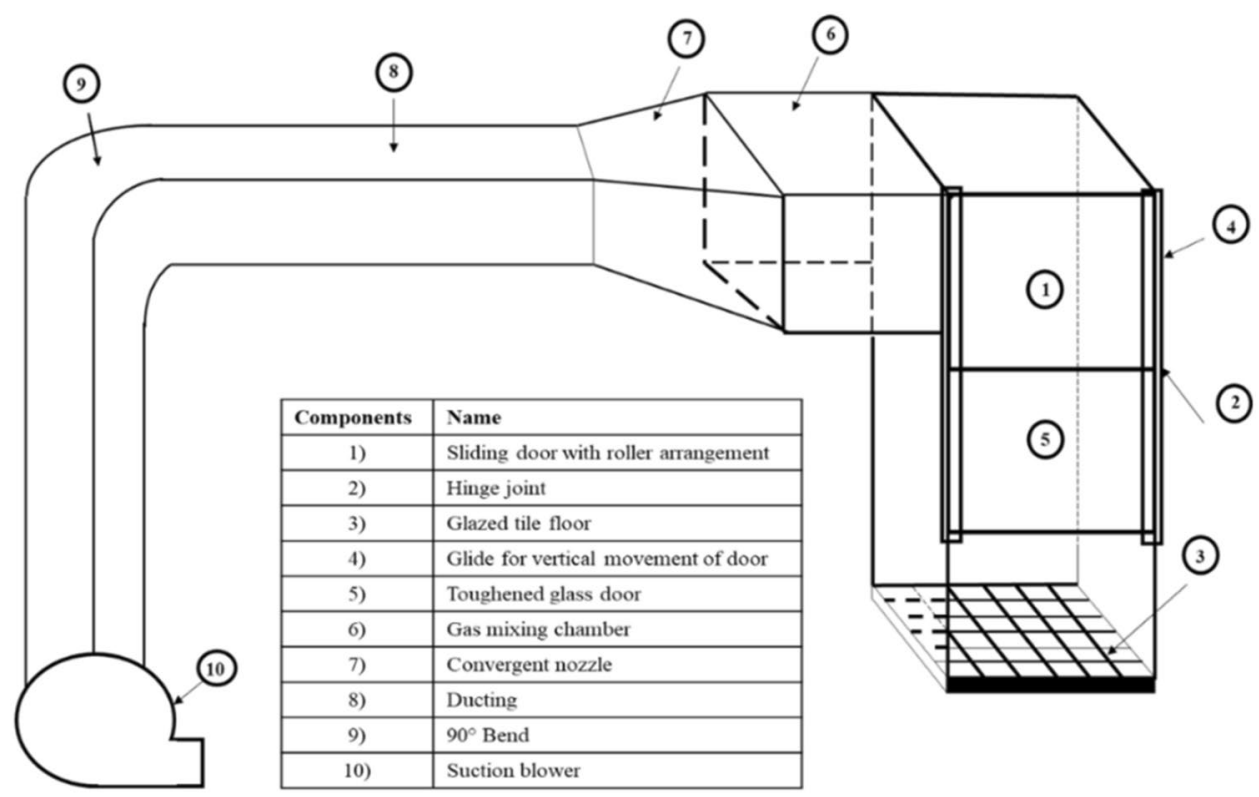

holding a hot stove, it is advised to use a handle. After the fabrication, the different view of the water jacket around the cookstove can be seen in Fig. S2 (a) and (b) (supplementary material), respectively. The width of the water jacket is $0.010 \mathrm{~m}$, so the current outside diameter cookstove with the water jacket and air gap is now $0.224 \mathrm{~m}$. Here, $0.003 \mathrm{~m}$ is a distortion effect during the fabrication of the water jacket, since it was very difficult to preserve such a small air gap using mild steel a thickness of $0.002 \mathrm{~m}$.

\section{Performance of cookstove}

In various countries, the number of cookstove testing procedures is used to determine the thermal efficiency of cookstove in both laboratory and field circumstances. One of the major protocols for laboratory experiments stated by BIS, which is generally used in different countries, is Water Boiling Test (WBT). In 2013, the Bureau of Indian Standards updated its old solid biomass cookstove test code [IS 13152 (Part 1): 1991] (Chulha). The test code was created with the goal of covering all of the requirements for various designs and types of solid biomass portable cookstoves for domestic, communal, and commercial use. Thermal efficiency testing, emission testing, quenching testing, and surface temperature testing are all covered [29]. In compliance with the protocol of the MNRE, the Water Boiling Test was carried out to this studies determine the thermal efficiency of the device. The water boiling testing starts with a sprinkling of $10 \mathrm{ml}$ of oil over the fuel bed, followed by the initiation of fire using a match stick. After initial ignition of bed, the speed of the fans (primary and secondary) was adjusted to get the best possible flame (speed, color, and smoke level), the cooking vessel having the required quantity of water in it was placed over the cookstove, while the time and temperature of water in the pot were noted down.

During the testing, the temperature of the water, the outer body of the cookstove, cooking pot, plate, and flame were measured at a regular interval of $5 \mathrm{~min}$. As soon as the temperature of water reached $95^{\circ} \mathrm{C}$, the first vessel was changed with the second one and the time taken for the boiling was recorded simultaneously. The same process was repeated until the fuel consumed completely and/or the flame disappeared, whichever is earlier. In case if the experiment does not last within an hour, the unconsumed fuel was taken out, weighted and the heating value was evaluated and recorded for mass and energy balance to calculate the thermal efficiency. The temperature of the outside surface of the stove was reported more than $104{ }^{\circ} \mathrm{C}$ during the test in a very short time, which means that there is huge potential of mitigating the conduction as well as radiation heat loss from the cookstove exterior skirt.

The thermal efficiency of cookstove without water jacket [29]

$\eta=\frac{\left[(n-1) \times\left(m_{p} \times C_{\mathrm{V}}+m_{\mathrm{w}} \times C_{\mathrm{W}}\right) \times\left(t_{2}-t_{1}\right)\right]+\left[\left(m_{p} \times C_{\mathrm{V}}+m_{\mathrm{w}} \times C_{\mathrm{W}}\right) \times\left(t_{3}-t_{1}\right)\right]}{\left[\left(X_{\mathrm{FUEL}} \times H_{\mathrm{FUEL}}\right)+\left(X_{\mathrm{P}} \times H_{\mathrm{P}}\right)\right]}$ 


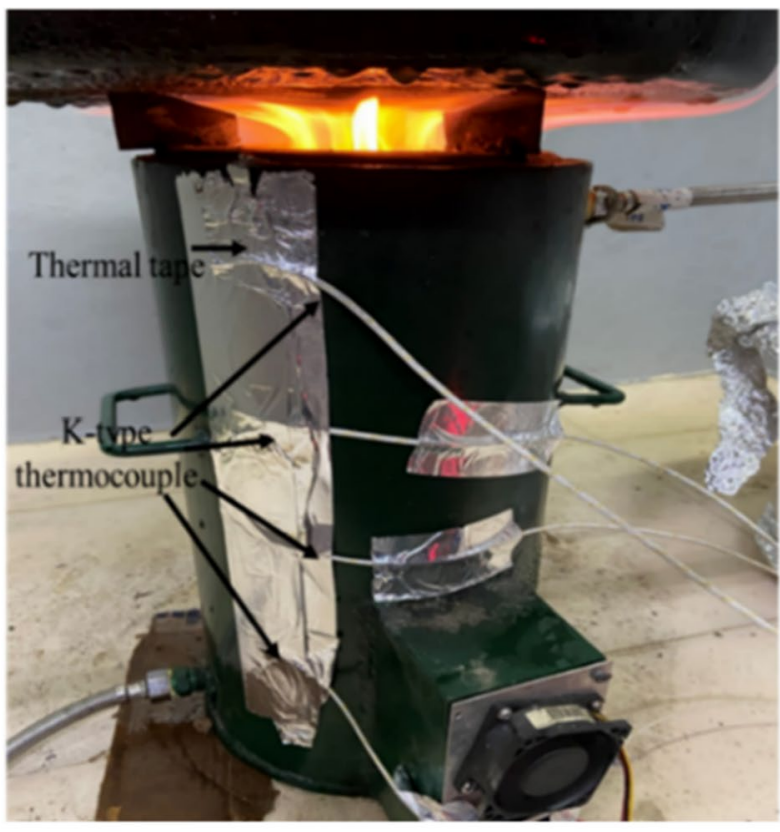

(a)

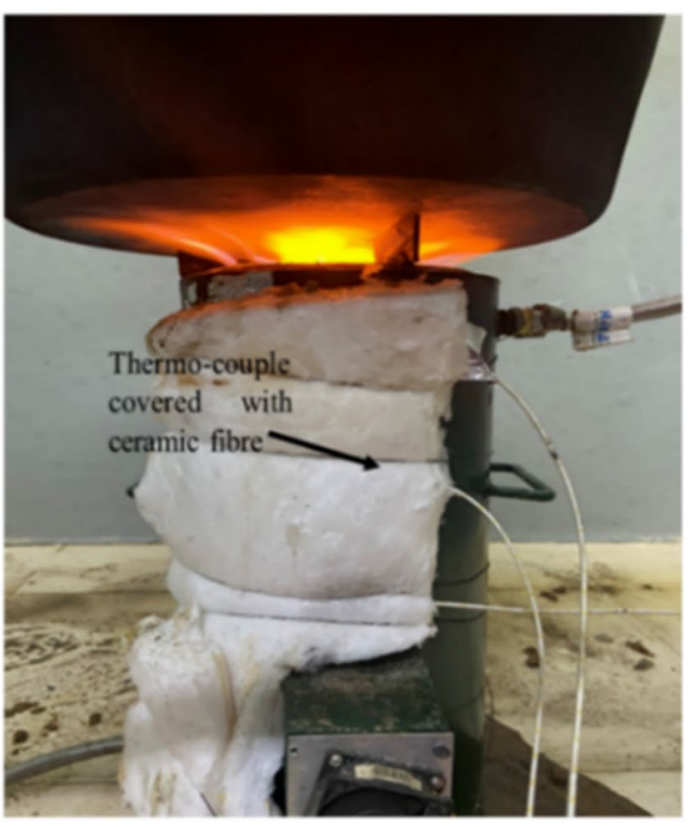

(b)

Fig. 8 Arrangements of measuring outermost wall temperature using K-type thermocouple

The thermal efficiency of cookstove with water jacket

in Fig. S3 (supplementary material). The PT-100 tempera-

$\eta=\frac{\left[(n-1) \times\left(m_{p} \times C_{\mathrm{V}}+m_{\mathrm{w}} \times C_{\mathrm{W}}\right) \times\left(t_{2}-t_{1}\right)\right]+\left[\left(m_{p} \times C_{\mathrm{V}}+m_{\mathrm{w}} \times C_{\mathrm{W}}\right) \times\left(t_{3}-t_{1}\right)\right]+\left[\left(m_{\mathrm{H}} \times C_{\mathrm{W}}\right) \times\left(t_{4}-t_{1}\right)\right]}{\left[\left(X_{\mathrm{FUEL}} \times H_{\mathrm{FUEL}}\right)+\left(X_{\mathrm{P}} \times H_{\mathrm{P}}\right)\right]}$

The K-type thermocouple was placed on the outer wall of the cookstove using thermal insulation and high-temperature sustainable tape (silver tape) for the assessment of outermost wall temperature, as seen in Fig. 8a. These measuring arrangements, as shown in Fig. 8b, cover with ceramic fiber (glass wool) for the precise calculation of temperature variation as the combustion bed travels down over the time as well to avoids air exposure otherwise temperature measurement will not be accurate. The temperature would also differ according to the variation in the water mass flow rate, so it is desired to take proper temperature calculation to find the effect of flow rate variation on the outermost wall temperature, as well as on cookstove efficiency. The water jacket outlet has been arranged on the upper most side of the water jacket. So that the cooking mechanism should not be disturbed and the waste heat can be recovered through counter flow of water, as the bed is moving down.

The hot water from the water jacket outlet is stored in a tank that is fully insulated with ceramic fiber using a hot water PVC pipe attachment, and the ceramic fiber is completely covered by aluminum-insulated tape to minimize the vessel's heat loss to the maximum degree possible as shown ture sensor has been arranged just below the collecting area for correct temperature measurement of the coming water through the outlet of the water jacket. The temperature calculated by PT-100 is connected by an 8-channel data logger, and it was noted every $5 \mathrm{~min}$, and the same was done with the cooking vessel kept over the cookstove.

\section{Results and discussions}

The water boiling test (WBT) was carried out with and without a water jacket to compare the thermal efficiency. Before and after the fabrication of the water jacket, the output parameters such as the thermal efficiency of the cookstove were evaluated on the same cookstove, and graphs were plotted on both instances. During the simulation, it was found that when the air gap is around $2 \mathrm{~mm}$, the water outlet temperature was reached more than $371.23 \mathrm{~K}$, but due to the fabrication constrain, it is strict to use a wide air gap between the outermost wall of the cookstove and water jacket. Thus, for simulation using the 2D axisymmetric model with the water jacket thickness of 
Fig. 9 Temperature contour of water temperature variation concerning increasing air-gap

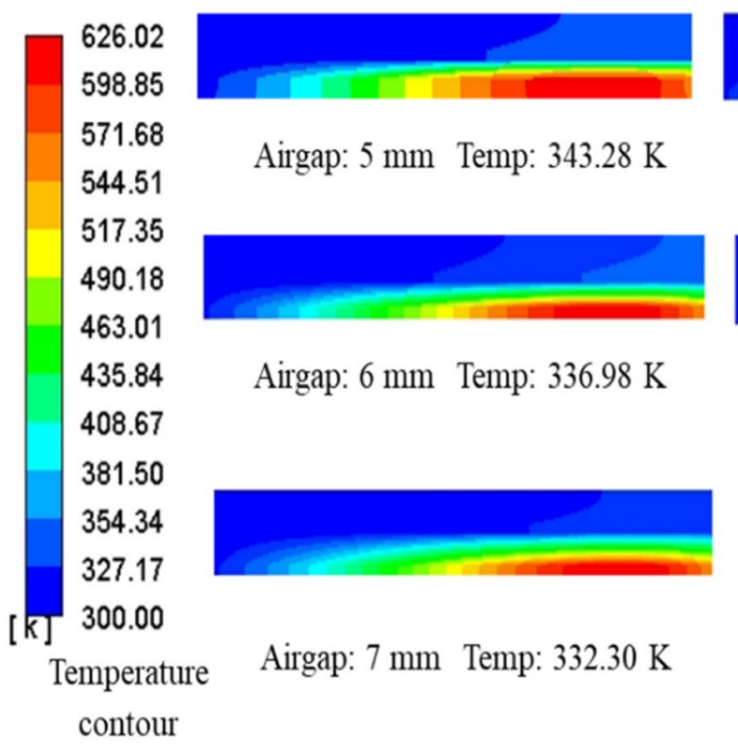

Airgap: 8 mm Temp: $328.6945 \mathrm{~K}$

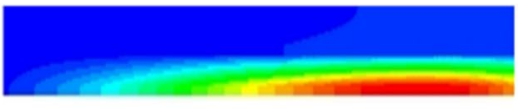

Airgap: $9 \mathrm{~mm}$ Temp: $325.84 \mathrm{~K}$

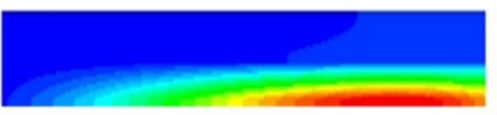

Airgap: $10 \mathrm{~mm}$ Temp: $323.51 \mathrm{~K}$

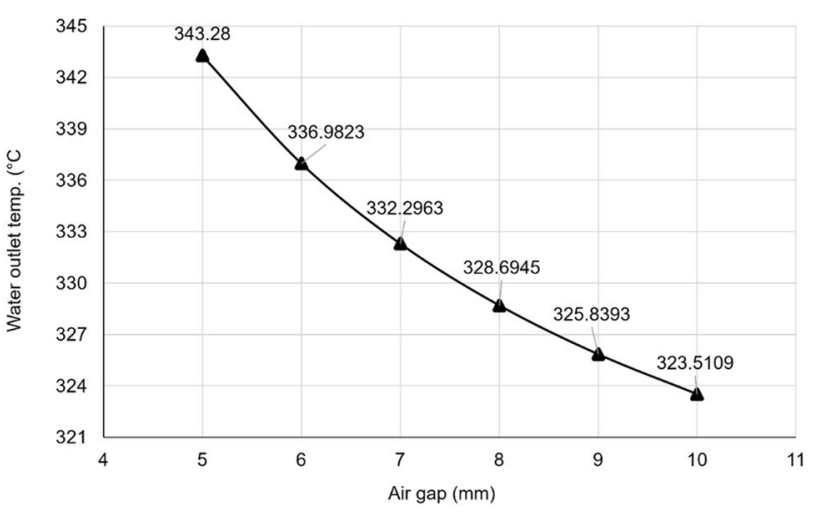

Fig. 10 Water temperature variation with respect to increasing air-gap

$0.01 \mathrm{~m}$ with standardized quadrilateral cell with $0.005 \mathrm{~m}$ of air gap was finalized for actual fabrication to the outermost wall of the cookstove. The grid-independent test was conducted with the number of numerical cells ranging from 55,000 to 284,000 and found that 127,500 of cells were ideal for simulation. The basic air-gap temperature contour is shown in Fig. 9. The schematic representation of the difference in temperature by maintaining the different air-gap is shown in Fig. 10. The fabrication of a water jacket has been completed along the outermost wall of the cookstove, retaining $0.005 \mathrm{~m}$ of air gap.

\section{Thermal efficiency}

The water boiling test was performed according to the MNRE protocol, and the thermal efficiency of the domestic forced draft cookstove was found around $33.17 \%$, implying that approximately $67 \%$ of the heat is being lost from the cookstove. The various losses through the stove wall

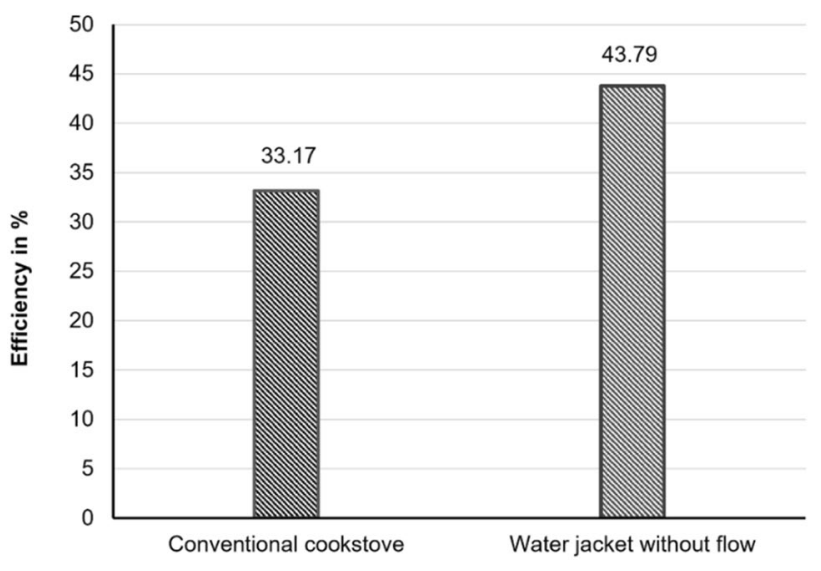

Fig. 11 Efficiency comparison with and without a water jacket

eventually decreased only by fabricating the water jacket, so the thermal efficiency of the cookstove is now $43.79 \%$, when there is no flow of water in the jacket. It implies that the efficiency increased by $32 \%$. The water jacket without any flow of water acts as insulation, which reduces the heat loss from the outer body and delivers it to the pot and improving the efficiency of the existing cookstove, as shown in Fig. 11.

The water starts flowing with a different mass, flow rate in the jacket has now been stored in an enclosed pot as shown in Fig. 8, to determine the total performance of the system, and the temperature has been continuously measuring using the PT-100 temperature sensor. At the moment, when combustion began, the initial temperature of the water has been noted and the final water temperature has been taken up to the point, when it starts decreasing, during the test. It was very difficult to maintain the flow rate of $0.002 \mathrm{~kg} / \mathrm{s}$ and when the flow rate was $0.002 \mathrm{~kg} / \mathrm{s}$, the temperature of the 
Table 2 Operating conditions

\begin{tabular}{llll}
\hline S. No & Flow rate $(\mathrm{kg} / \mathrm{s})$ & $\begin{array}{l}\text { Water supplied } \\
\text { in liter }\end{array}$ & $\begin{array}{l}\text { Initial } \\
\text { Temp. } \\
\left({ }^{\circ} \mathrm{C}\right)\end{array}$ \\
\hline 1 & 0.002 & 12.72 & 14.6 \\
2 & 0.003 & 19.80 & 13.8 \\
3 & 0.004 & 28.32 & 12 \\
4 & 0.005 & 34.80 & 15.2 \\
5 & 0.006 & 36.36 & 14.8 \\
6 & 0.007 & 41.16 & 14.2 \\
\hline
\end{tabular}

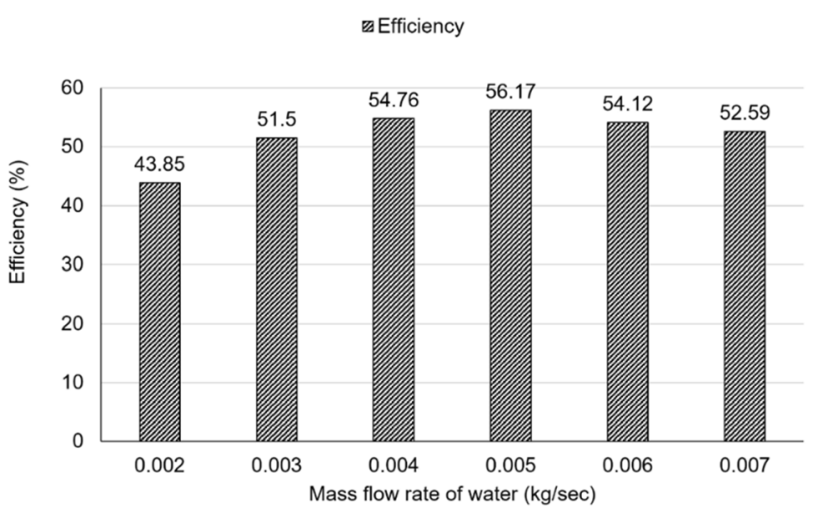

Fig. 12 Overall efficiency at a different mass flow rate

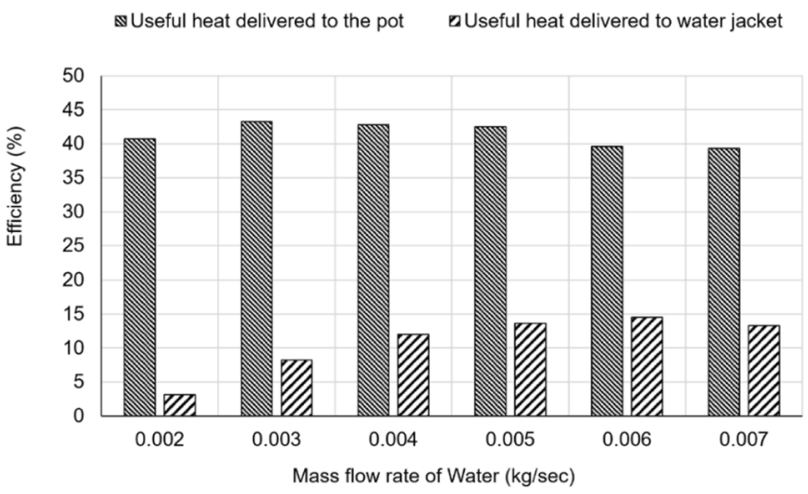

Fig. 13 Useful heat delivered to the pot and water jacket

water more than $91^{\circ} \mathrm{C}$, which is already more than sufficient for any household application such as washing utensils or bathing purposes, or as pre-heated water supply to solar still basin [30], so there is no need to maintain such small flow rate. The maximum amount of water has been vaporized during the test, and a very less amount of water has been received in the enclosed pot when the flow rate was minimum and vice-versa.

The total efficiency is equal to, the useful heat supplied to the pot and the heat gained by the water flowing in the

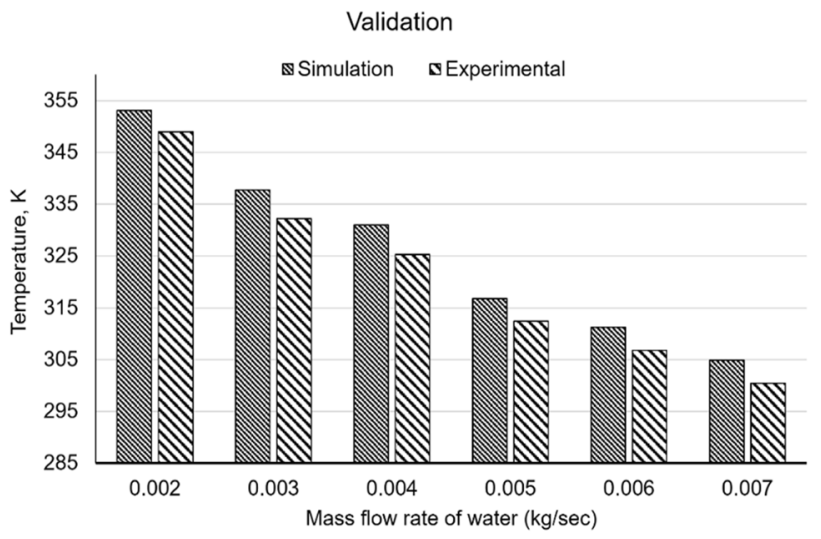

Fig. 14 Validation of simulation results with experimental results

water jacket during the experiment. As the mass flow rate increases, less usable heat is going to the pot whereas more heat gain by the water circulating in the jacket, but in total, the overall efficiency increases. The operating condition is shown in Table 2 and increases the overall efficiency of the cookstove by adding the yield as shown in Fig. 12. It was also observed that there is a marginal decline in overall efficiency when the mass flow rate rises above $0.005 \mathrm{~kg} / \mathrm{s}$ because less heat is going to the pot as well as to the water flowing in the jacket as shown in Fig. 13. Computational values were checked by equating similar geometrical and operational parameters with the experimental findings, as shown in Fig. 14. The maximum and minimum percentage of deviation in temperature was about $1.76 \%$ and $1.16 \%$, respectively, as compared to the experimental value. The simulation results were found to be in good agreement with the experimental results (less than 2\%).

All three modes of heat transfer take place here during the process, convective, and radiative heat transfer from the outermost wall of the cookstove and transfer it to the innermost wall of the water jacket, and from there, heat is transferring to the water through conduction, so when the mass flow rate of water is minimum, the contact time will be more and more heat gained by the water and this suited up the water temperature results in a huge amount of water get vaporized. The flow rate is having a huge impact on efficiency, and it is realized that when the mass flow rate increases above $0.005 \mathrm{~kg} / \mathrm{s}$, the pot efficiency starts decreasing and water jacket efficiency gets increased, but when the flow rate was above $0.006 \mathrm{~kg} / \mathrm{s}$, the heat gain by water flowing in the jacket also starts decreasing, so that overall efficiency has been decreased. The temperature gain by the water in the pot, as well as the water streaming in the jacket, is very less when the mass flow rate is above $0.005 \mathrm{~kg} / \mathrm{s}$, while the water loss is very less, but no substantial temperature gain, so there is also no need to go beyond this mass flow rate.

When comparing all three cases, like: 


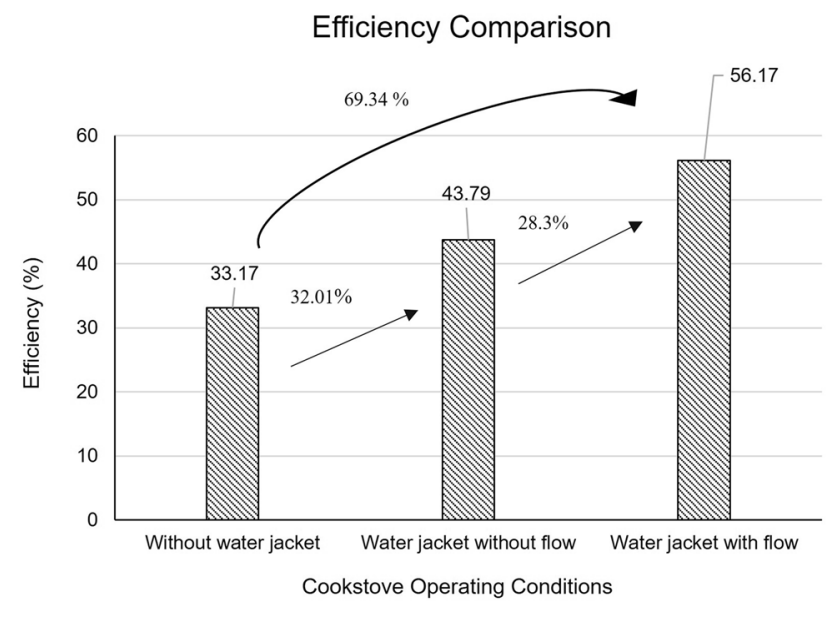

Fig. 15 Efficiency comparison of different cases

Case 1. Cookstove without water jacket (conventional cookstove)

Case 2. Cookstove with water jacket with zero mass flow rate of water and

Case 3. Cookstove with water jacket with varying mass flow volume.

Based on the water boiling test, the thermal efficiency of conventional domestic forced draft cookstove was found to be of $33.17 \%$ but after fabricating a water jacket around the cookstove even without flow of water, the efficiency has increased up to $43.79 \%$ ( $32 \%$ increment); which is attributed to the reduced heat loss to the surroundings as the additional air gap (i.e. the water jacket) behaves like an insulation. On the other hand, the thermal efficiency has increased up to $56.17 \%$ when the water flow rate has taken to 0.005 $\mathrm{kg} / \mathrm{s}$ in the water jacket. There is a significant improvement (69.3\% and $28.3 \%$, respectively) in the thermal efficiency of the cookstove as compared to the first two cases (cases 1 and 2), as can be seen clearly in Fig. 15.

\section{Sensitive analysis}

During the experiment, it was discovered that the highest amount of water was vaporized, while the flow rate was lowest, and vice versa. The flow rate and air gap affected the temperature of hot water received from the water jacket outlet. As a result, the flow rate and air gap are the most important parameters in the sensitive study of heat and mass transfer process. Exogenous factors or relationships between variables are frequently included in simulation models, yet our knowledge of them is typically insufficient. Sensitivity analysis is the process of assessing which of the guesses are truly important, and whether a slightly altered guess will have a major impact on the model's behavior [31]. In this scenario, the water input temperature was varied; it was determined by the day's ambient temperature. The experiment was conducted in the last week of December, when the water input temperature was quite low, ranging from 14.6, $13.8,12,15.2,14.8$, and $14.2{ }^{\circ} \mathrm{C}$, with flow rates of 0.002 , $0.003,0.004,0.005,0.006$, and $0.007 \mathrm{~kg} / \mathrm{s}$, respectively.

When comparing the temperature gain at different airgaps while maintaining the same flow rate, it was discovered that the temperature variation is very small. For example, when the flow rate is maintained at $0.002 \mathrm{~kg} / \mathrm{s}$ for a $25 \%$ variation in air gap, the temperature only varies by $4 \%$ in the case of maximum temperature gain by the water, and for the $0.008 \mathrm{~kg} / \mathrm{s}$ flow rate, the temperature variation is only up to $4.5 \%$. When comparing the temperature gain by water at different flow rates while keeping the same air-gap, it was discovered that when the mass flow rate varies from $0.002-0.008 \mathrm{~kg} / \mathrm{s}$ while keeping the air gap $6 \mathrm{~mm}, 7 \mathrm{~mm}$, and $8 \mathrm{~mm}$, respectively, temperature gain up to $21.99 \%$, $23.76 \%$, and $22.16 \%$. Fig. 16 depicts the temperature gain and hot water produced at a specific mass flow rate of water. Because of the aforementioned research, it can be stated that when the two variable parameters, air gap and mass flow rate of water, are compared, the mass flow rate is the more sensitive parameter.

\section{Uncertainty analysis}

The error occurred in the measuring instruments is calculated in this section. The minimum error that occurred in any instrument is equal to the ratio between its least count and minimum value of the output measured. It is important to quantify the divergence in experimental results due to the accuracy of instruments used for data measurement. When $Q$ is the function of a number of independent variable $x_{1}$,

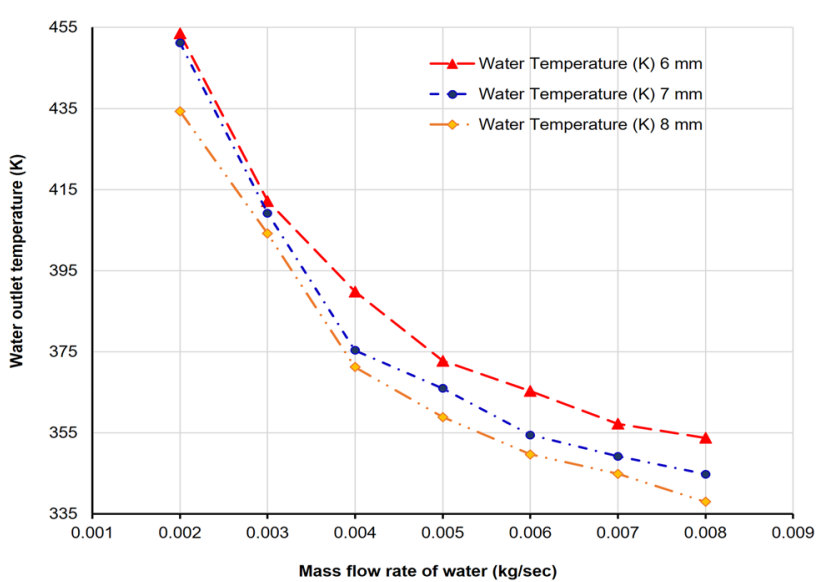

Fig. 16 Temperature gain at different mass flow rate and air gap 
$x_{2}, x_{3}, \ldots \ldots x_{n}$ and $z_{1}, z_{2}, z_{3}, \ldots \ldots . . z_{n}$ are their corresponding uncertainty, then in $Q$ can be estimated by the following relation:

$$
\begin{aligned}
U_{Q}= & {\left[\left(\frac{\partial Q}{\partial x_{1}} z_{1}\right)^{2}+\left(\frac{\partial Q}{\partial x_{2}} z_{2}\right)^{2}+\left(\frac{\partial Q}{\partial x_{3}} z_{3}\right)^{2}\right.} \\
& \left.+\cdots \cdots \cdots+\left(\frac{\partial Q}{\partial x_{n}} z_{n}\right)^{2}\right]^{\frac{1}{2}}
\end{aligned}
$$

The uncertainty associated with the calculation of thermal efficiency has been evaluated using the least count/ accuracy of the instruments that were being collected the data during experiments. The value of uncertainty involved in the calculation of thermal efficiency was found to be in the range of $2.65 \%-2.81 \%$.

\section{Conclusions}

The improved cookstove with a water jacket has been tested to reduce the heat loss from the outermost wall of a domestic forced draft cookstove. To determine the thermal performance, WBT has been done and this has been conducted at the IIT Delhi campus $\left(28.6139^{\circ} \mathrm{N}, 77.2090^{\circ} \mathrm{E}\right)$ in the biomass combustion test laboratory (WS-206) with and without a water jacket. The results showed that the thermal efficiency of the conventional cookstove was $33.17 \%$, while the efficiency increases after fabrication of jacket and found $43.79 \%$ of modified cookstove having the water jacket without any flow. Thus, there is an increment of $32.01 \%$ in thermal efficiency as compared to the first case. The overall efficiency was measured as the usable heat supplied to the pot and heat obtained by the water flowing in the water jacket, continuously increasing up to the flow rate of $0.005 \mathrm{~kg} / \mathrm{s}$ and reaches $56.17 \%$, which is $69.34 \%$ and $28.3 \%$ more as compared from the first two cases.

The maximum gain in efficiency is at $0.005 \mathrm{~kg} / \mathrm{s}$, and it starts declining above this flow rate, like when the flow rate was $0.006 \mathrm{~kg} / \mathrm{s}$ and $0.007 \mathrm{~kg} / \mathrm{s}$, the efficiency was $54.12 \%$ and $52.59 \%$, respectively. Thus, it was observed that the flow rate of $0.005 \mathrm{~kg} / \mathrm{s}$ is adequate to achieve the maximum overall efficiency without altering the actual cooking job, and the obtained hot water is very useful in household applications and decreases the burning of additional biomass or fuel, that has to burn in heating of water in many in rural houses. This water jacket fabrication not only produces hot water but also lowers the emissions due to less combustion of biomass fuels, so it can provide two-type of products in a single burning, i.e., cooking of food as well as producing hot water.
Supplementary Information The online version contains supplementary material available at https://doi.org/10.1007/s40095-021-00430-z.

Acknowledgements One of the authors (SKS) gratefully acknowledges the financial assistance in the form of a research fellowship due to the Indian Institute of Technology Delhi for the study. The fruitful comments and suggestions provided by learned reviewers are also highly appreciated to make the article in the present form.

Authors' contribution S. K. Singh contributed to investigation, formal analysis, writing-original draft; S. C. Kaushik contributed to review and supervision; V. V. Tyagi contributed to review and supervision S. K. Tyagi contributed to conceptualization, review and overall supervision.

Funding This research did not receive any specific grant from funding agencies in the public, commercial, or not-for-profit sectors.

\section{Declarations}

Conflict of interest The authors declare that they have no known competing financial interests or personal relationships that could have appeared to influence the work reported in this paper.

\section{References}

1. Sinha, C.S., Venkata, R.P., Joshi, V.: Rural energy planning in India designing effective intervention strategies. Energy Policy 22, 403-414 (1994). https://doi.org/10.1016/0301-4215(94)90169-4

2. Jana, C., Bhattacharya, S.C.: Sustainable cooking energy options for rural poor people in India: an empirical study. Environ. Dev. Sustain. 19(3), 921-937 (2017). https://doi.org/10.1007/ s10668-016-9774-y

3. IEA: World Energy Outlook-2019, based on WHO Household Energy Database and IEA World Energy Balances (2019)

4. Gupta, A., Mulukutla, A.N., Gautam, S., Tane Khan, W., Waghmare, S.S., Labhasetwar, N.K.: Development of a practical evaluation approach of a typical biomass cookstove. Environ. Technol. Innov. 17, 100613 (2020). https://doi.org/10.1016/j.eti.2020. 100613

5. Bronowski, J.: The ascent of man. Little Brow and Company, Boston (1973)

6. Kumar, M., Kumar, S., Tyagi, S.K.: Design, development and technological advancement in the biomass cookstoves: a review. Renew. Sustain. Energy Rev. 26, 265-285 (2013). https://doi.org/ 10.1016/j.rser.2013.05.010

7. Sedighi, M., Salarian, H.: A comprehensive review of technical aspects of biomass cookstoves. Renew. Sustain. Energy Rev. 70, 656-665 (2017). https://doi.org/10.1016/j.rser.2016.11.175

8. Approved Models of Cook-stoves. http://164.100.94.214/appro ved-models-cook-stoves (2020). Accessed 30 Nov 2020

9. World Health Organization: The World Health Report 2002Reducing Risks, Promoting Healthy Life. World Health Organization, Geneva (2002)

10. World Health Organization: The World Health Report 2006Working Together for Health. World Health Organization, Geneva (2006)

11. Gill, J.: Improved stoves in developing countries: a critique. Energy Policy 15(2), 135-144 (1987). https://doi.org/10.1016/ 0301-4215(87)90121-2 
12. Tyagi, S.K.: Biomass pellet based combustion devices. Patent No. 20557/2018-DEL (2018)

13. Himanshu, Pal, K., Jain, S., Tyagi, S.K.: Development of advanced biomass cookstove and performance comparisons using the modified star rating methodology. Energy Eng. 118(5), 1237-1251 (2021). https://www.techscience.com/energy/v118n5/43825

14. Senthil Rajan, A., Raja, K., Marimuthu, P.: Increasing the productivity of pyramid solar still augmented with biomass heat source and analytical validation using RSM. Desalin. Water Treat. 57(10), 4406-4419 (2016). https://doi.org/10.1080/19443994. 2014.995133

15. Maneewan, S., Chindaruksa, S.: Thermoelectric power generation system using waste heat from biomass drying. J. Electron. Mater. 38(7), 974-980 (2009). https://doi.org/10.1007/ s11664-009-0820-5

16. Champier, D., Bedecarrats, J.P., Rivaletto, M., Strub, F.: Thermoelectric power generation from biomass cook stoves. Energy 35(2), 935-942 (2010). https://doi.org/10.1016/j.energy.2009.07. 015

17. Ma, H.K., Lin, C.P., Wu, H.P., Peng, C.H., Hsu, C.C.: Waste heat recovery using a thermoelectric power generation system in a biomass gasifier. Appl. Therm. Eng. 88, 274-279 (2015). https://doi. org/10.1016/j.applthermaleng.2014.09.070

18. IEA: SDG7: Data and Projections, IEA, Paris. https://www.iea. org/reports/sdg7-data-and-projections (2020). Accessed $30 \mathrm{Nov}$ 2020

19. Tyagi, S.K., Pandey, A.K., Sahu, S., Bajala, V., Rajput, J.P.S.: Experimental study and performance evaluation of various cookstove models based on energy and exergy analysis. J. Therm. Anal. Calorim. 111(3), 1791-1799 (2013). https://doi.org/10.1007/ s10973-012-2348-9

20. Hankey, S., Sullivan, K., Kinnick, A., Koskey, A., Grande, K., Davidson, J.H., Marshall, J.D.: Using objective measures of stove use and indoor air quality to evaluate a cookstove intervention in rural Uganda. Energy Sustain. Dev. 25, 67-74 (2015). https://doi. org/10.1016/j.esd.2014.12.007

21. Mishra, A.: Fuel for the clean energy debate-a study of fuel wood collection and purchase in rural India. In: South Asian Network for Development and Environment Economics (SANDEE). Kathmandu, Nepal. Policy Brief (2008)
22. Johnson, M.A., Pilco, V., Torres, R., Joshi, S., Shrestha, R.M., Yagnaraman, M., Lam, N.L., Doroski, B., Mitchell, J., Canuz, E., Pennise, D.: Impacts on household fuel consumption from biomass stove programs in India, Nepal, and Peru. Energy Sustain. Dev. 17(5), 403-411 (2013). https://doi.org/10.1016/j.esd.2013. 04.004

23. Masera, O.R., Diaz, R., Berrueta, V.: From cookstoves to cooking system: the integrated program on sustainable household energy use in Mexico. Energy Sustain. Dev. 9(5), 25-36 (2005). https:// doi.org/10.1016/S0973-0826(08)60480-9

24. Bussmann, P.J.T., Visser, P., Prasad, K.K.: Open fires: Experiments and theory. Proc. Indian Acad. Sci. Sect. C Eng. Sci. 6(1), 1-34 (1983). https://doi.org/10.1007/BF02843288

25. Shah, R., Date, A.W.: Steady-state thermochemical model of a wood-burning cook-stove. Combust. Sci. Technol. 183(4), 321346 (2011). https://doi.org/10.1080/00102202.2010.516617

26. Chaney, J., Liu, H., Li, J.: An overview of CFD modelling of small-scale fixed-bed biomass pellet boilers with preliminary results from a simplified approach. Energy Convers. Manag. 63, 149-156 (2012). https://doi.org/10.1016/j.enconman.2012.01.036

27. Wah-Yen, T., Asako, Y., Sidik, N.A.C., Rui-Zhe, G.: Governing equations in computational fluid dynamics: derivations and a recent review. Prog. Energy Environ 1, 1-19 (2017)

28. ANSYS Fluent Theory Guide (2017) Vol 18.1

29. Bureau of Indian Standards, 2013: Indian standard on portable solid biomass cookstove (Chulha First Revision). IS 13152 (Part 1) (2013)

30. Singh, S.K., Tyagi, S.K., Kaushik, S.C.: Desalination using waste heat recovery with active solar still. In: Bose, M., Modi, A. (eds.) Proceedings of the 7th International Conference on Advances in Energy Research. Springer Proceedings in Energy. Springer, Singapore (2021). https://doi.org/10.1007/978-981-15-5955-6_42

31. Clemson, B., Tang, Y., Pyne, J., Unal, R.: Efficient methods for sensitivity analysis. Syst. Dyn. Rev. 11(1), 31-49 (1995). https:// doi.org/10.1002/sdr.4260110104

Publisher's Note Springer Nature remains neutral with regard to jurisdictional claims in published maps and institutional affiliations. 